\title{
Forms and materials used in exterior spaces and their effect on interior lighting conditions
}

\author{
M. Miri \\ Sibeh Co. Ltd. Qazvin, Iran
}

\begin{abstract}
Some results such as a more comfortable city, less energy needed for indoor comfort, saving money, and reduction in the emission of green house gasses are just some of the benefits of sustainable urban design. Suitable use of natural light as an important factor in sustainability must always be considered in the design process. The Building form and aperture type are the most influential factors that affect interior conditions, energy consumption and energy cost in the buildings. Although there are many lighting experts, sustainability and urban designers, few of them are professional in the field that bridges the gap between these disciplines. So, I decided to conduct a research on the subject assessing the effect of exterior space on interior conditions. All the proposals I will introduce in this paper originated from simultaneously using my experience in light and daylight design and my knowledge as an architect in the field of urban and landscape design. The method I applied in this paper is trial and error that it is an empirical method for achieving defined goals. In this paper, simple forms and materials will be proposed for reducing illuminance in a $25 \mathrm{~m}^{2}$ room in the summer, in Tehran. And then, its effects in the winter are analyzed. All in all, the main goal of this paper is introducing a method that can be used in designing sustainable buildings, spaces and even cities. We can apply similar methods in sustainable urban and regional design to reach a greener world with a healthier environment. Keywords: day light, exterior material, landscape, interior illuminance. reflectance, sustainability.
\end{abstract}

\section{Introduction}

Sustainability that is an attempt to provide the best outcomes for the human and natural environments both now and into the indefinite future plays a very influential role in preserving the environment. Sustainability affects every level 
of organization, from the local neighborhood to the entire planet. On the other hand, urban design concerns the arrangement, appearance and functionality of towns and cities focuses on public space including the totality of spaces that are used freely on a day-to-day basis by general public. This encompasses streets and parks together with public infrastructure and privately-owned places. Combining urban design with sustainability, we should define Sustainable design that is the art of designing physical objects to comply with the principles of economic, social, and ecological sustainability. It ranges from the microcosm of designing small objects for everyday use, through to the macrocosm of designing buildings, cities, and the earth's physical surface. Urban and rural planning can benefit from including sustainability as a central criterion when laying out roads, streets, buildings and other components of the built environment

In the climatically optimum city, the thermal comfort and even the health of some city-dwellers improve. Less energy is needed for indoor temperature control. Peak power demand is reduced, while saving on the cost of city infrastructure. Therefore, the main goal of this paper is introducing some proposals helping approach to these types of cities.

\section{Use of optimum amount of daylight in the buildings}

Many known reasons can justify considering daylight as a light source in the buildings. Daylight can affect the functional arrangement of spaces, occupant comfort (visual and thermal), structure, and energy use in the building, as well as the type and use of electric light and associated control systems. In fact, if daylight is considered a viable source of light in the building, no phase of the building design process will be unaffected; therefore, all the aspects of the building design process, from urban planning to interior design, and from predesign analysis and programming to construction, are influenced.

The combined reduction of building energy use, cooling energy use, and peak energy use that often results from day lighting can reduce the total energy cost of a building, and consequently, increase probability of reaching to a sustainable city.

Side lighting is the simplest and oldest system used for daylighting interior spaces. In addition to entering natural light, another so much important benefit of daylight apertures is that they provide visual communication channels to the outside; that is, they offer the building's occupants a view

Light, whether it is daylight or electric light, adds heat to a building. About 55 percent of the thermal energy in solar radiation is in the visible spectrum. So this energy must be removed through a cooling process. So, direct sunlight should be excluded from buildings by shading devices, as it can result in overheating, thermal discomfort, and excessive glare. The method that helps us to design a room providing both a good view for its occupants without any restricting obstructions, and suitable interior condition is always a challenge for designers. Applying suitable exterior forms and materials for approaching this aim is tried in this paper. 
The natural light that comes in the buildings is composed of direct and indirect sun light and sky light. Light reflected from ground, light reflected from obstruction, and light internally reflected are the composition of indirect light. So, for reducing adverse effects of natural light, effects of using different exterior forms and materials on them must be taken into account in the design process.

\section{Defining the project}

In this paper, the software for analyzing these effects is Dialux 4.3 , and usually trial and error method is used to achieve the aims. The goal of the paper is to introduce a method that can be used in designing the landscape of one-story buildings in a small town in north of Tehran. Its main goal is not only maintaining views for buildings occupants but also reducing energy consumption and peak demand especially in the summer all over the site. The concentration of this paper is appraising effects of alternations in exterior forms and materials on interior lighting condition in a $5 \mathrm{mx} 5 \mathrm{~m}$ room. In the analysis process, there are no artificial or natural obstructions that obstructed entering of day light into buildings. This method is an alternative for where we can't use deciduous trees that are used for shading the southern facades in the summer and letting day light enter to the interiors in the winter.

Because of the sun position in the summer, it is the most critical time that must be considered for cooling load. 12:00, and 9:00am or 3:00 pm on 21st June are selected for assessing proposed forms and materials. Then, 21st December, and equinox time are chosen for analyzing those forms and materials. Decreasing cooling load in the summer is far more effective on energy consumption and peak demand than reducing heating load in the winter because cooling process has much more energy consumption and higher cost than heating process. Therefore, more attention should be given to the former.
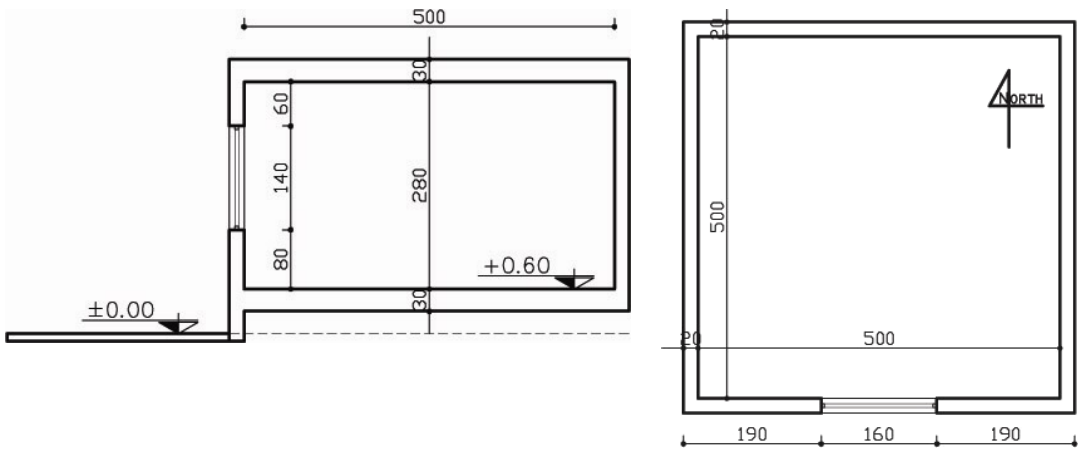

Location: North of Tehran, Iran.

\section{Room Specifications:}

Glass Transmission: 90\%

Ceiling reflection: $80 \%$

Walls reflection: $50 \%$

Floor reflection: $20 \%$

Figure 1: Room specifications. 


\section{Designing procedure}

The procedure, applied in this project, is made up of a series of phases that will be done chronologically.

\subsection{Define a critical distance from the room}

The goal of this phase is to define a critical distance that materials, with different reflectances, greatly affect interior lighting conditions. In this process, different distances are analyzed.

\section{Workplane Specification:}

Height: $0.80 \mathrm{~m}$

Grid: $32 \times 32$ Points

Boundary Zone: $0.50 \mathrm{~m}$

Values in Lux

Light Loss Factor: 0.80

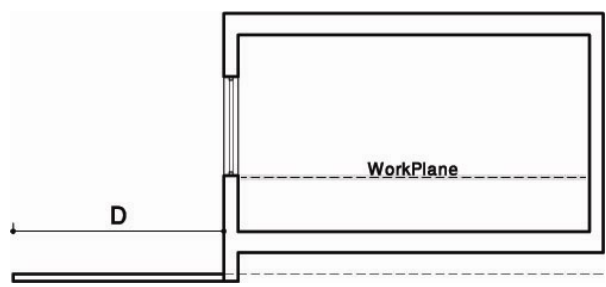

Exterior Surface Reflectance: 90\%

Average Illuminance on the Workplane in the room at12:00 on 21/06

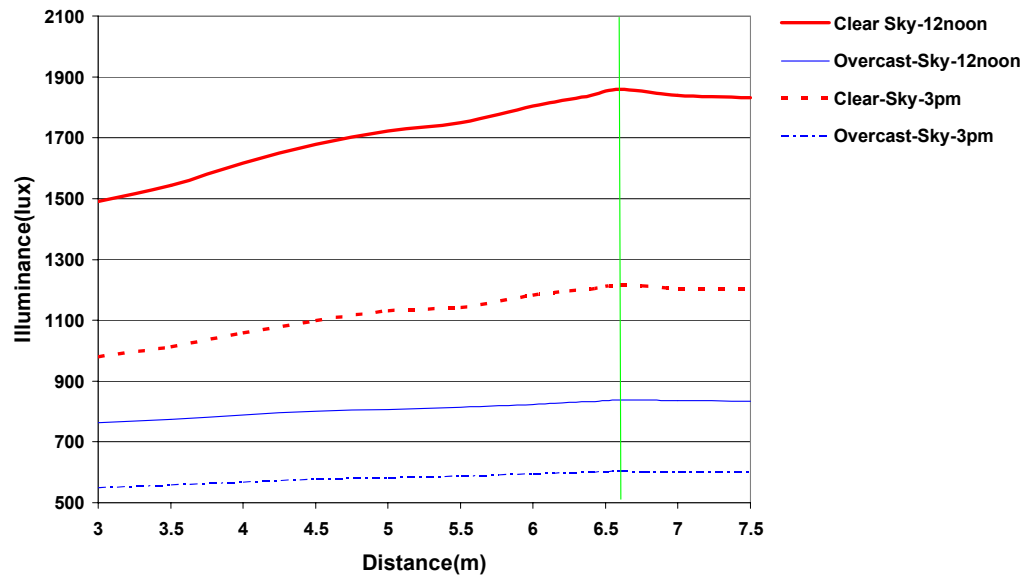

Figure 2: Critical distance outside the room.

Because of what this diagram shows, $\mathrm{D}=6.6 \mathrm{~m}$ is selected.

\subsection{Creating an exterior wedge shape form}

As a prerequisite, because of access, maintenance, movement, etc, it needs a $1.5 \mathrm{~m}$ width footpath beside the buildings.

In this section, a wedge shape form shown in Figure 3 is introduced. It plays two important roles in the design; first, it reflects sun rays far from windows in the summer time, and second, it prevents discomfort glare issued from snow in the winter. Its suggested height is $0.5 \mathrm{~m}$, and now, its length must be looked out. 


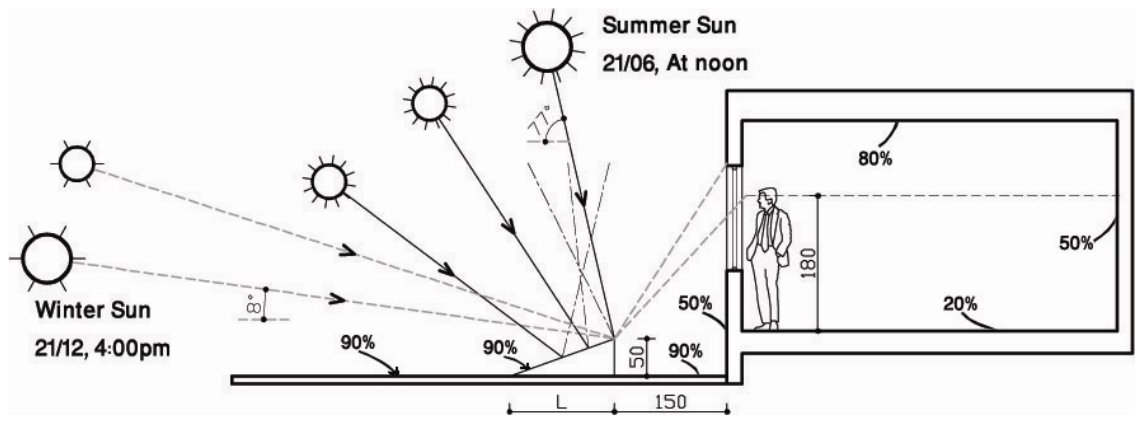

Figure 3: $\quad$ Proposed wedge shape form for its exterior.

Table 1: Average illuminance on the workplane for different Length on 21/06.

\begin{tabular}{|c|c|c|c|c|c|}
\hline Sky Condition Length & $\mathbf{1 . 3 m}$ & $\mathbf{1 . 4 m}$ & $\mathbf{1 . 4 5 m}$ & $\mathbf{1 . 5 m}$ & $\mathbf{1 . 6 m}$ \\
\hline Clear Sky-12noon & 1652 & 1649 & 1654 & 1653 & 1653 \\
\hline Overcast-Sky-12noon & 799 & 795 & 797 & 795 & 798 \\
\hline Clear-Sky-3pm & 1095 & 1091 & 1095 & 1094 & 1094 \\
\hline Overcast-Sky-3pm & 576 & 573 & 575 & 573 & 576 \\
\hline
\end{tabular}

After carefully considering these results, $\mathrm{L}=1.4$ is proposed.

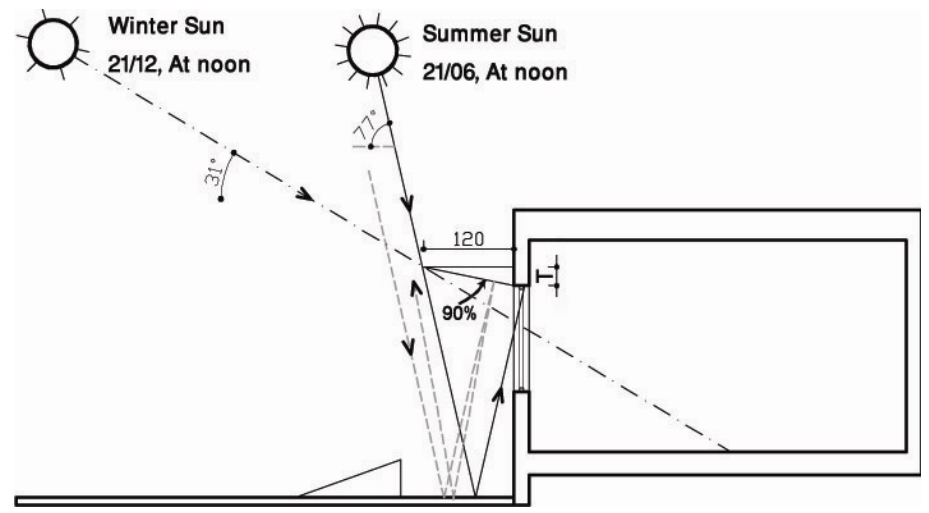

Figure 4: Proposal sunshade for obscuring direct sun in the hot summer.

\subsection{Proposing a kind of sunshade}

In this section, an overhang will be used and its effects on the interior lighting conditions will be analyzed. Its main aim is reducing direct sun rays entering the room in the summer, and not missing the heat gain from them in the winter. It is 
obvious that the more the width of it, the more it obscures the sun. In this project, an overhang with $1.2 \mathrm{~m}$ width is chosen and its optimum thickness must be found.

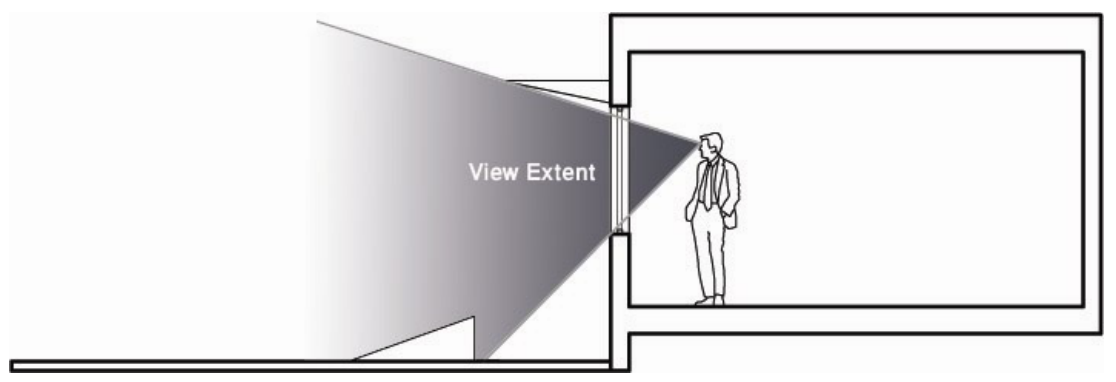

Figure 5: With a triangular section, the view extent of an interior observer is increased.

Table 2: Average illuminance on the workplane for different Length on $21 / 06$.

\begin{tabular}{|c|c|c|c|c|c|}
\hline T & $\mathbf{1 0 c m}$ & $\mathbf{1 5 c m}$ & $\mathbf{2 0 c m}$ & $\mathbf{2 5 c m}$ & $\mathbf{3 0 c m}$ \\
\hline Clear Sky-12noon & 1829 & 1806 & 1826 & 1754 & 1728 \\
\hline Overcast-Sky-12noon & 548 & 542 & 543 & 544 & 549 \\
\hline Clear-Sky-3pm & 1249 & 1239 & 1228 & 1218 & 1211 \\
\hline Overcast-Sky-3pm & 397 & 393 & 390 & 391 & 394 \\
\hline
\end{tabular}

There is not so much difference between $\mathrm{W}=25 \mathrm{~cm}$ and $\mathrm{W}=30 \mathrm{~cm}$ in interior light intensity, and, we choose the less $(\mathrm{W}=25 \mathrm{~cm})$.

\subsection{Offering a boxwood}

For reducing glare caused by snow in the winter and also reducing indirect sun light entering the room in the summer, we use boxwood. The distance between the boxwood and proposed wedge shape is chosen $1.2 \mathrm{~m}$ and its height must be found.

In accordance with what Figure 7 shows, the minimum height of boxwood is $72 \mathrm{~cm}$. Apparently, the more its height, the less average illuminance in the room. $75 \mathrm{~cm}$ height will be selected. Now, its effects on lighting conditions in the room will be analyzed. Its result is in Table 3 .

\subsection{Separation the surface between the wedge shape form and boxwood}

In this section, the surface between wedge shape zone and boxwood divided into two surface; one with $90 \%$ reflectance that is close to boxwood, and the other with $30 \%$ reflectance. 
Now, for finding its proper width that have influential effect on interior lighting conditions the following table will be shown. With carefully considering these results and also their effects on aesthetic features in the landscape, $0.4 \mathrm{~m}$ is selected.

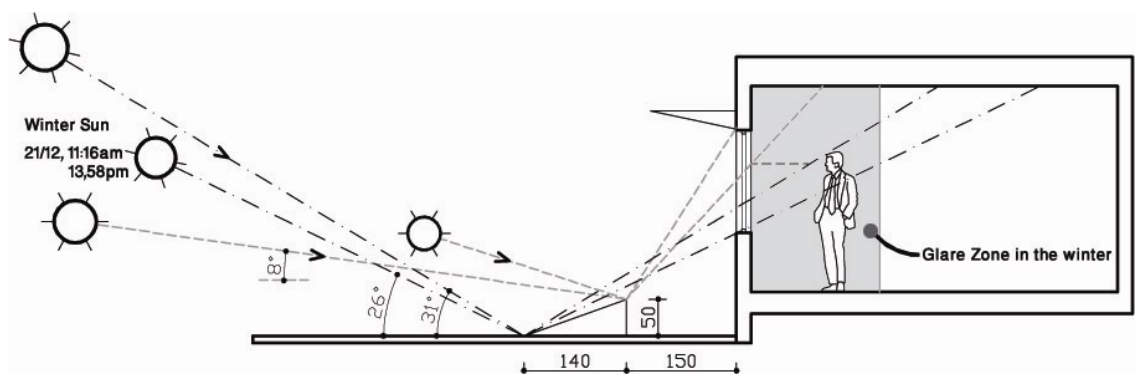

Figure 6: Glare zone shown is between 11:16am and 13:58pm on 21/12.

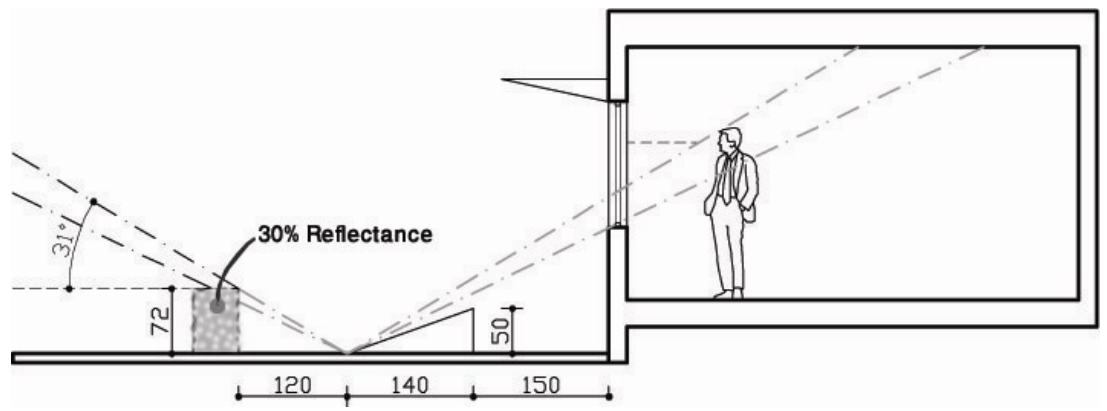

Figure 7: Finding the height of boxwood according to the angle of incoming sun ray and $3.1 \mathrm{~m}$ distance between it and the room.

Table 3: $\quad$ Average illuminance on the workplane on 21/06.

\begin{tabular}{|c|c|c|}
\cline { 2 - 3 } \multicolumn{1}{c|}{} & Without Boxwood & With Boxwood \\
\hline Clear Sky-12noon & 1754 & 1494 \\
\hline Overcast-Sky-12noon & 544 & 482 \\
\hline Clear-Sky-3pm & 1218 & 1058 \\
\hline Overcast-Sky-3pm & 391 & 349 \\
\hline
\end{tabular}

\subsection{Assesing alternation in the street coating next to the buildings}

As you see in the Figure 9, analyzing how much light intensity alternates when we change denoted surface reflectance will be done in this phase.

As this result shows, the interior light intensity change between $10 \%$ and $90 \%$ reflectance in material used behind the boxwood is too little that we can ignore it. Therefore, concrete can be chosen as the cover of the street instead of asphalt, so it decreases and optimizes electric energy consumption greatly at night and also don't affect interior lighting conditions between sunrise and sunset time. 


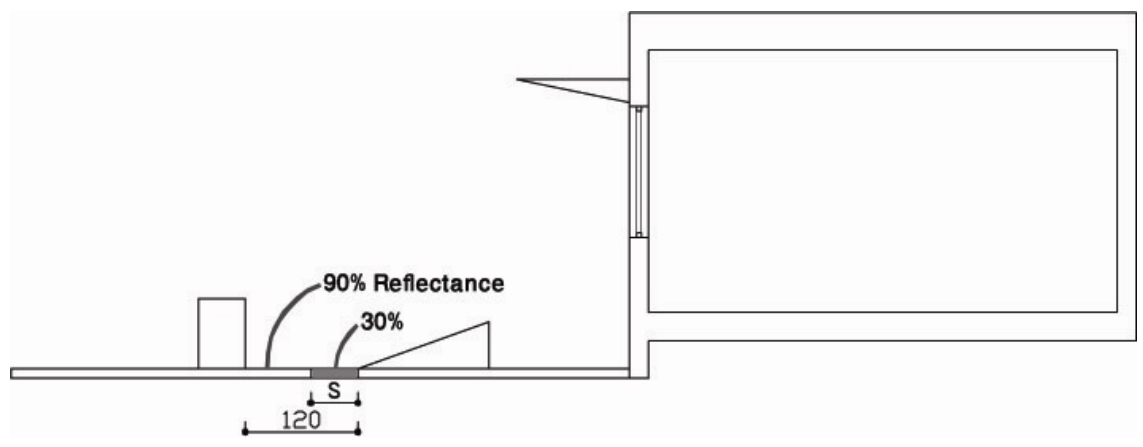

Figure 8: $\quad$ Finding width of the surface with $30 \%$ reflectance.

Table 4: Average illuminance on the workplane for different Length on 21/06.

\begin{tabular}{|c|c|c|c|c|c|c|}
\cline { 2 - 7 } \multicolumn{1}{c|}{} & $\mathbf{1 . 2} \mathbf{m}$ & $\mathbf{1 m}$ & $\mathbf{0 . 8 m}$ & $\mathbf{0 . 6 m}$ & $\mathbf{0 . 4 m}$ & $\mathbf{0 . 2 m}$ \\
\hline Clear Sky-12noon & 1342 & 1348 & 1359 & 1405 & 1430 & 1464 \\
\hline Overcast-Sky-12noon & 458 & 458 & 462 & 471 & 473 & 478 \\
\hline Clear-Sky-3pm & 954 & 961 & 976 & 1007 & 1025 & 1041 \\
\hline Overcast-Sky-3pm & 332 & 332 & 335 & 341 & 343 & 346 \\
\hline
\end{tabular}

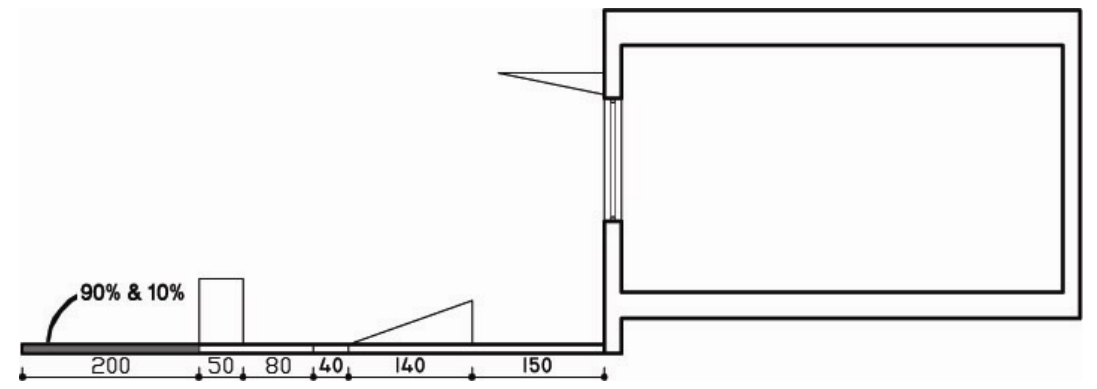

Figure 9: Assessing alternation in the reflectance of shown surface.

Table 5: Average illuminance on the workplane in the room for different reflectance for the shown surface on 21/06.

\begin{tabular}{|c|c|c|}
\cline { 2 - 3 } \multicolumn{1}{c|}{} & $\mathbf{9 0 \%}$ & $\mathbf{1 0 \%}$ \\
\hline Clear Sky-12noon & 1395 & 1383 \\
\hline Overcast-Sky-12noon & 471 & 469 \\
\hline Clear-Sky-3pm & 1005 & 997 \\
\hline Overcast-Sky-3pm & 341 & 339 \\
\hline
\end{tabular}




\subsection{Assesing alternation in sidewalk materials beside the buildings}

As you see in the Figure 10, the effects of using materials with various reflectances on the emphasized surface will be studied in this section.

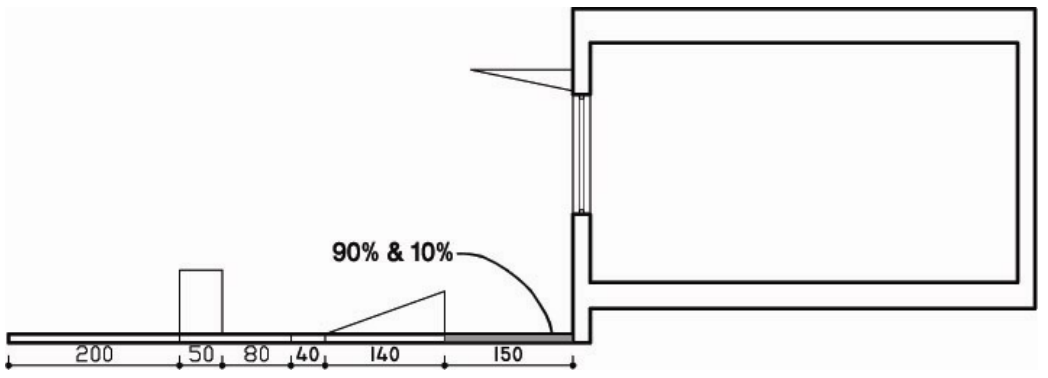

Figure 10: Assessing alternation in the reflectance of shown surface.

Table 6: Average illuminance on the workplane in the room for different reflectance on $21 / 06$.

\begin{tabular}{|c|c|c|}
\cline { 2 - 3 } \multicolumn{1}{c|}{} & $\mathbf{9 0 \%}$ & $\mathbf{1 0 \%}$ \\
\hline Clear Sky-12noon & 977 & 644 \\
\hline Overcast-Sky-12noon & 392 & 337 \\
\hline Clear-Sky-3pm & 726 & 476 \\
\hline Overcast-Sky-3pm & 284 & 244 \\
\hline
\end{tabular}

What these results show is that the amount of difference in the interior illuminance between $90 \%$ and $10 \%$ in a sunny day is such that materials with low reflectance are proposed.

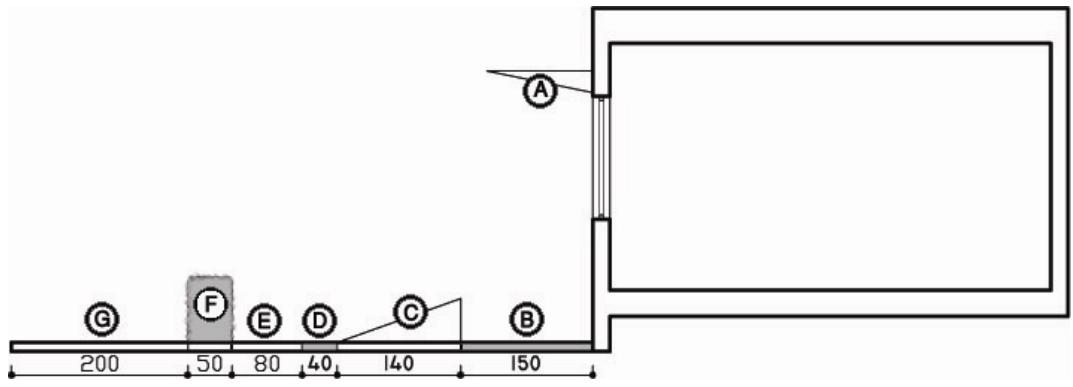

Figure 11 . 


\subsection{Defining criteria for selecting exterior materials}

All things considered, for selecting suitable materials, the following criteria inferred from the aforesaid sections:

- A: because of its shape, a kind of metal will be used;

- B: because of its effect on interior lighting conditions in the summer, material with low reflectance is used (section 4.7);

- $\quad$ C: all things considered, a lawn surface is proposed;

- D: according to what is said in the aforesaid explanations, material with low reflectance will be used (section 4.5);

- E: with similar reason, material used is with medium reflectance (section 4.5);

- F: boxwood is used (section 4.4);

- $\quad$ : in regard to what is said in the aforesaid explanations, material used is with medium reflectance (section 4.6).

\section{Selecting suitable materials}

In accordance with their reflectances, we choose relevant materials that are both suitable for interior conditions and enhance aesthetic features of buildings' exteriors. The materials proposed for the selected items are in Table 7:

Table 7: $\quad$ Proposed materials for A to G.

\begin{tabular}{|c|c|c|}
\cline { 2 - 3 } \multicolumn{1}{c|}{} & Selected Material & Reflectance(\%) \\
\hline A & Aluminum, polished & $60 \%$ \\
\hline B & Granite & $25 \%$ \\
\hline C & Grass & $30 \%$ \\
\hline D & Brick, dark buff & $35 \%$ \\
\hline E & Terra-cotta, white & $70 \%$ \\
\hline F & Boxwood & $20 \%$ \\
\hline G & Concrete & $40 \%$ \\
\hline
\end{tabular}

Table 8: All the values calculated are average illuminance in the room on $21 / 06$.

\begin{tabular}{|c|c|c|c|c|}
\cline { 3 - 5 } \multicolumn{2}{c|}{} & $\begin{array}{c}\text { 21st, } \\
\text { June }\end{array}$ & $\begin{array}{c}\text { 21st, } \\
\text { December }\end{array}$ & Equinox \\
\hline $\begin{array}{c}\text { Proposed } \\
\text { Exterior }\end{array}$ & Clear Sky-12noon & 701 & 4289 & 2084 \\
\cline { 2 - 5 } & Overcast-Sky-12noon & 346 & 183 & 246 \\
\cline { 2 - 5 } & Clear-Sky-3pm & 520 & 568 & 1683 \\
\cline { 2 - 5 } & Overcast-Sky-3pm & 251 & 85 & 154 \\
\hline \multirow{3}{*}{$\begin{array}{c}\text { Simple } \\
\text { Exterior }\end{array}$} & Clear Sky-12noon & 1223 & 7486 & 7885 \\
\cline { 2 - 5 } & Overcast-Sky-12noon & 717 & 379 & 509 \\
\cline { 2 - 5 } & Clear-Sky-3pm & 808 & 787 & 2201 \\
\cline { 2 - 5 } & Overcast-Sky-3pm & 519 & 176 & 319 \\
\hline
\end{tabular}


Applying these materials in comparison with a situation having a simple surface like concrete with $40 \%$ reflectance is shown in Table 8 .

What this table shows is that with this simple change in the exterior of the buildings, we can greatly reduce heat gain in the room in the summer. This proposal and similar ones can be applied for landscape design in a sustainable urban planning procedure.

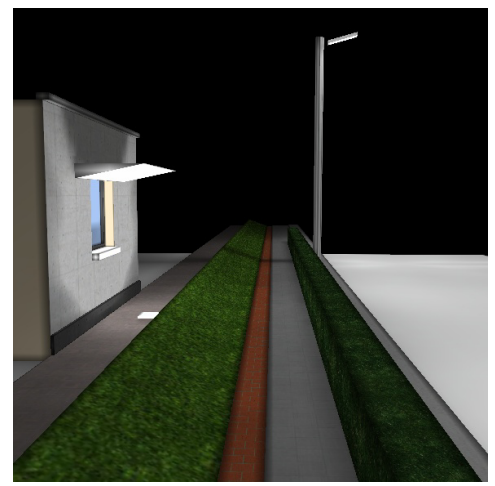

Figure 12: The 3D picture of the proposal at night.

\section{References}

[1] Robbins, Claude L., Day lighting: design and analysis, New York, Van Nostrand Reinhold, 1986

[2] M. David Egan, Concepts in Architectural Lighting, College of Architecture Clemson University, McGraw-Hill Publishing Company, 1983

[3] http://www.dial.de 